\title{
Sobre la calle Carrión y la bartonelosis
}

\author{
Carlos Osorio Abarzúa
}

'Programa de Microbiología y Micología, Instituto de Ciencias Biomédicas (ICBM), Facultad de Medicina, Universidad de Chile.

Recibido: 16 de mayo de 2019

Correspondencia a: Carlos Osorio Abarzúa gonosorio@med.uchile.cl

\section{About Carrion street and bartonellosis}

Daniel Alcides Carrión (1857-1885) was a Peruvian medical student who established the relationship between the clinical entities called Oroya fever and Peruvian wart, until then independent diseases. By autoinoculation of Peruvian wart extracts from a patient, he contracted the Oroya fever. This fact showed that both clinical entities occurred due to the same cause. Subsequent investigation showed that the agent involved was the bacteria Bartonella bacilliformis. On the other hand, a street called Carrion is located in front of the Faculty of Medicine of the University of Chile. It is a legend or medical tradition in this Faculty that this street is named in honor of this Peruvian martyred student. This work shows that this medical story has no historical basis and analyzes its true origin.

Keywords: Carrion; bartonellosis; history of Medicine; Chile.

Palabras clave: Carrión; bartonelosis; historia de la Medicina; Chile.

\section{Introducción}

$\mathrm{N}$ o fuimos pocos los estudiantes de Medicina que escuchamos de parte de nuestros profesores de Microbiología de la Facultad de Medicina de la Universidad de Chile que la calle que se localiza inmediatamente frente a la entrada principal de nuestra Facultad, denominada calle Carrión, había sido nombrada de tal manera en honor a un estudiante peruano mártir de la medicina. Tal relato parecía totalmente factible para nosotros, pues el estudiante de medicina Daniel Alcides Carrión había vivido y muerto en la segunda mitad del s. XIX y dicha calle tenía su nombre desde, al menos, la misma época. La historia era perfecta y cumplía con su objetivo de encantar al joven estudiante con un evento local, heroico y trágico.

\section{Mito y leyenda}

El mito y la leyenda son relatos que se divulgan en forma oral, de una generación a otra. Son narraciones que nacen espontáneamente como una expresión colectiva de una raza o pueblo, debido a una necesidad de crear una imagen del mundo y una necesidad de manifestar una fe. En ellos participan seres y hechos sobrenaturales ${ }^{1}$. Según la Real Academia de la Lengua Española (RAE), el mito corresponde a "una narración maravillosa situada fuera del tiempo histórico y protagonizada por personajes de carácter divino o heroico". En cambio, una leyenda es definida como una: "relación de sucesos que tienen más de tradicionales o maravillosos que de históricos o verdaderos". Es decir, la leyenda a diferencia del mito, se sustenta muchas veces en eventos históricos. De acuerdo a estas definiciones la tradición o relato analizado en esta nota correspondería más bien a una leyenda, pues como se verá más adelante se sustenta en hechos históricos locales que fueron alterados con un fin educativo.

\section{Daniel Alcides Carrión (1857-1885)}

Daniel Alcides Carrión García nació en la ciudad de Cerro de Pasco, Perú central, en 1857. Sus progenitores fueron el médico y abogado ecuatoriano José Baltazar Carrión y Torres y la peruana María Dolores García Navarro $^{2}$. Dicha ciudad era en ese entonces un importante asentamiento minero, principalmente de plata, donde la mayoría de sus habitantes eran inmigrantes que provenían de todos los rincones de dicho país o del mundo y que se congregaron allí atraídos por sueños de riqueza. El joven Carrión se trasladó en 1871 a Lima para cursar sus estudios secundarios en el Colegio de Nuestra Señora de Guadalupe. Dicho colegio era el más afamado de su país en ese entonces y era donde se educaba a los hijos de la clase alta ${ }^{3}$.

Posteriormente, Daniel Carrión ingresó a la Facultad de Medicina de la Universidad de San Marcos en 1880 y cuando cursaba su quinto año de la carrera llegaron a la comunidad médica las noticias sobre los nuevos y espectaculares descubrimientos sobre los gérmenes y su participación en enfermedades infecciosas. En este contexto, a inicios de agosto de 1885, la Academia Libre de Medicina de Lima convocó a un concurso para realizar memorias sobre la etiología y anatomía patológica de la verruga peruana. El 27 de agosto de 1885, el joven Daniel Carrión decidió inocularse el suero extraído de las verrugas de un paciente. Las razón de esto no es 
del todo clara, pero al parecer, su principal motivo para proceder de esta manera fue conocer el pródromo de la enfermedad con el fin de poder tratarla oportunamente ${ }^{4}$. El 17 de septiembre siguiente, presentó abruptamente un cuadro caracterizado por malestar general, artralgias, fiebre, escalofríos, polidipsia e insomnio. El cuadro se agravó rápidamente y el joven Carrión falleció en Lima el 5 de octubre de 1885 (Figura 1).

La enfermedad de Carrión o bartonelosis humana es una enfermedad infecciosa causada por la bacteria Bartonella bacilliformis, perteneciente a la clase alpha del phylum Proteobacteria y relacionada con el orden Rickettsiales. Es una enfermedad transmitida por artrópodos, principalmente el mosquito Lutzomya verrucarum. Una vez inoculado el agente en el hospedero, éste invade la sangre e ingresa a sus eritrocitos y células endoteliales. Luego de un breve período de incubación, se inicia la fase febril que se caracteriza clínicamente por presentar malestar general, fiebre, mialgias, artralgias, cefalea y el desarrollo de una anemia aguda hemolítica. Luego prosigue una etapa intermedia asintomática que puede perdurar por algunas semanas. Finalmente, el cuadro evoluciona a una etapa caracterizada por la aparición de lesiones cutáneas angioproliferativas, que pueden persistir durante meses o años ${ }^{5}$.

\section{La calle Carrión o callejón de los Carriones}

Esta calle corresponde a un antiguo camino de la Chimba (sector trans-Mapocho que etimológicamente en quechua significa "al otro lado del río") que conectaba la Cañadilla (actual calle Independencia) y el callejón de la Hornillas (actual calle Fermín Vivaceta) en la comuna de Independencia. En varios mapas de la segunda mitad del siglo XIX es posible observar un callejón en dicho sector denominada calle de Carrión (ver por ejemplo plano de Santiago de 1887) ${ }^{6}$. Hasta este punto la conexión parecía ser verosímil. Se recurrió luego a los registros de la $\mathrm{Mu}-$ nicipalidad, pero no había datos que explicaran por qué la calle se denominaba de esa manera. Decidí entonces buscar planos de Santiago de la primera mitad del s. XIX. Dichos planos son muy escasos, pero afortunadamente existe uno de excelente calidad publicado por Claudio Gay en 1831 en su obra Historia Física y Política de Chile 7 . Mirando detalladamente dicho plano, y analizando específicamente la ubicación de calle de Carrión, encontré para mi asombro que en dicho lugar había un callejón denominado "callejón de los Carriones" (Figura 2). La verdad se manifestaba en toda su crudeza. La tradición médica sobre la calle Carrión no era verdadera. Era imposible, que dicha calle se hubiera denominado así en honor al estudiante Daniel Alcides Carrión que recién habría de nacer 26 años después de la confección del plano. Ante

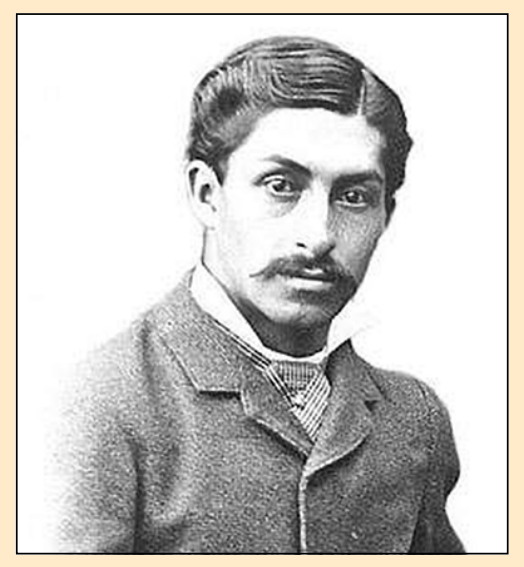

Figura 1. Fotografía de Daniel Alcides Carrión.

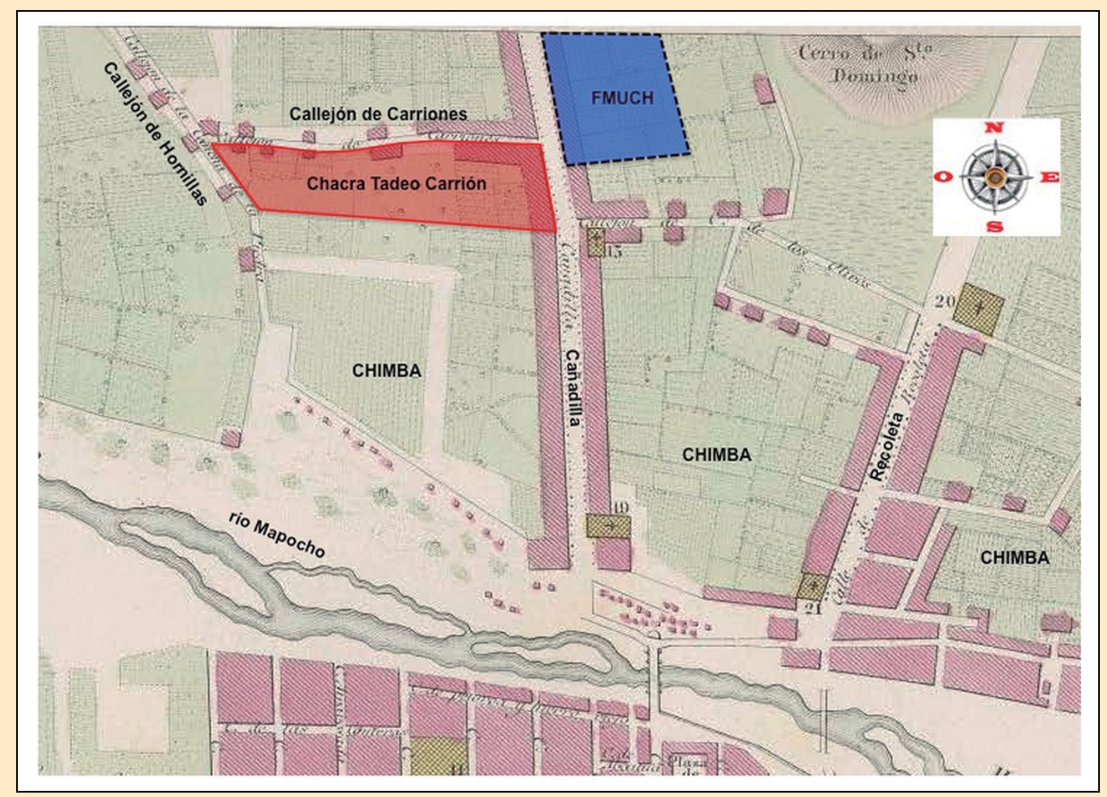

Figura 2. Detalle del sector de la Chimba al norte del río Mapocho. Se observa el callejón de Carriones que une la Cañadilla (actual avenida Independencia) y el callejón de la Cancha de la Piedra o de las Hornillas (actual calle Fermín Vivaceta). La localización de la actual Facultad de Medicina de la Universidad de Chile (FMUCH) se muestra en línea punteada y en color azul. La chacra de Tadeo Carrión se muestra en color rojo. Una rosa de los vientos en el extremo superior derecho indica los puntos cardinales. Modificado de plano de Claudio Gay de 1831.

tal situación, la única posibilidad honrosa era investigar las verdaderas raíces históricas de dicha denominación.

\section{Familia Carrión en la Chimba}

Pero si el nombre Carrión no derivaba del estudiante mártir Daniel Alcides Carrión de quién derivaba entonces? La tarea por delante no era nada fácil. En esa encrucijada, la única posibilidad era revisar cuidadosamente documentos antiguos del archivo de Escribanos y Notarios 
de Santiago de Chile, esperando encontrar escrituras o testamentos que demostrasen que una familia Carrión criolla había vivido en dicho lugar. Y la búsqueda fue más que satisfactoria. El primer propietario de tierras en dicho lugar y apellidado de dicha manera fue don Agustín Carrión Briones. Este señor era nieto de Vicente Carrión Montecinos, nacido en España en 1569 y muerto en Chile en 1623. Hijo de Vicente Carrión y doña María Flores fue don Juan Carrión Flores, quien contrajo matrimonio con María Briones y tuvo una numerosa descendencia, siendo uno de sus hijos el mencionado Agustín. Agustín Carrión Briones, el primer propietario de ese apellido en el lugar, relata en su testamento de 1782 junto a su esposa Mariana Vega que posee tres cuadras de tierra junto a la Cañadilla ${ }^{8}$. El matrimonio Carrión Vega tuvo a su vez varios hijos, siendo el más destacado Tadeo Carrión Vega. Tadeo Carrión y su esposa Antonia Plaza legalizaron su testamento con fecha 1 de abril de 1812 ante el notario Ramón Ruiz de Rebolledo9. En dicho documento traspasaron a su numerosa descendencia las tierras y la viña que tenían cercanas a la Cañadilla, que Tadeo había heredado de sus padres y que por su deslinde norte las delimitaba un callejón en ese entonces innominado. Las tierras de Tadeo Carrión se subdividieron entre sus numerosos hijos formando varias quintas con su frente norte mirando a dicho callejón, y probablemente por esa razón, a inicios del s. XIX, dicho sendero o camino pasó a denominarse callejón de los Carriones. Como se puede observar, la familia Carrión en Chile pertenecía a un antiguo linaje criollo y no tenía relación alguna con el estudiante peruano Daniel Alcides Carrión.

\section{Epílogo}

Las leyendas suelen tener una base real. En este caso, por una parte se encuentra al estudiante peruano Daniel Alcides Carrión y por otra parte a la familia Carrión de la Cañadilla. Ambos son hechos históricos. Sin embargo, el hecho fortuito de que compartieran el mismo apellido, seguramente incentivó a algunos médicos a simplificar la realidad y a crear un relato épico. Ésta relataba que la calle se había denominado así en honor a dicho estudiante mártir. La familia Carrión y el estudiante habían vivido durante el siglo XIX, por lo que su antigüedad aseguraba de algún modo su verosimilitud y al mismo tiempo la dificultad de su contraste factual. Seguramente, el fin perseguido era divulgar entre los estudiantes de medicina una historia de ribetes trágicos, que pudiera estimular su joven imaginación y revelarles que hay veces que en aras de conseguir un objetivo superior el sacrificio es un camino honorable. Lamentablemente el relato no es real, pero su objetivo permanece intacto. La búsqueda de nuevos incentivos para motivar a nuestras actuales generaciones de médicos a seguir caminos que muchas veces implican grandes sacrificios.

Agradecimientos: Quisiera agradecer a varios colegas del Programa de Microbiología del Instituto de Ciencias Biomédicas (ICBM) que accedieron a leer y criticar este trabajo y así ayudaron a mejorar sustancialmente su presentación.

\section{Resumen}

Daniel Alcides Carrión (1857-1885) fue un estudiante de Medicina peruano que estableció la relación causal entre los cuadros clínicos denominados fiebre de Oroya y la verruga peruana, hasta ese entonces entidades independientes. Mediante la autoinoculación de extractos de verrugas peruanas de un paciente, él mismo contrajo la fiebre de Oroya. Este hecho demostró que ambos cuadros clínicos se debían a la misma causa. La investigación posterior mostró que el agente involucrado era la bacteria Bartonella bacilliformis. Por otra parte, frente a la Facultad de Medicina de la Universidad de Chile se ubica la calle denominada Carrión. Es una tradición médica en dicha Facultad que esta calle se denomina así en honor a este estudiante peruano mártir. Esta investigación muestra que esta tradición médica no tiene fundamento histórico y analiza su verdadero origen.

\section{Referencias bibliográficas}

1.- Profesor en Línea. Mito y leyenda. Disponible en: http:// www.profesorenlinea.cl/ castellano/MitoyLeyenda.htm (Fecha de acceso: 20 de enero de 2019).

2.- Álvarez R. La ascendencia paterna de Daniel Alcides Carrión. An Fac Med 2008; 69:206-211. Disponible en sitio: http://www.scielo.org.pe/ (Fecha de acceso: 5 de marzo de 2019).

3.- García-Cáceres U. Daniel Alcides Carrión. Acta Méd Per 2006; 23: 48-51. Disponible en: http://www.scielo.org.pe/ (Fecha de acceso: 25 de marzo de 2019).

4.- Pamo O. Daniel Carrión: mito y realidad. Rev Med Hered 2003; 14: 214-220. Disponible en: http://www.scielo.org.pe/ $\mathrm{pdf} / \mathrm{rmh} / \mathrm{v} 14 \mathrm{n} 4 / \mathrm{v} 14 \mathrm{n} 4 \mathrm{~h} 1 . p d f$ (Fecha de acceso: 15 de enero de 2018).

5.- Murray P, Rosenthal K y Pfaller M. Capítulo 29: Otros bacilos gramnegativos. En Microbiología Médica, $8^{\circ}$ Edición, Ed. Elsevier España, Barcelona, España, 2017.

6.- Fuentes FA. Plano de Santiago de Chile 1887. Disponible en: http://www.archivovisual.cl/plano-de-santiago-3. (Fecha de acceso: 10 de noviembre de 2018).

7.- Gay C. Mapa de Santiago de Chile 1831. Disponible en: http://www.memoriachilena.gob.cl/602/w3-article-127132. html (Fecha de acceso: 15 de noviembre de 2018).

8.- Luque L. Archivo Escribanos de Santiago. Volumen 791; Año: 1782. Archivo Nacional Histórico, Santiago, Chile.

9.- Ruiz-Rebolledo R. Archivo Notarial Santiago. Volumen 40; Año 1812. Archivo Nacional Histórico, Santiago, Chile. 